\title{
Downregulation of high mobility group protein box-1 resensitizes ovarian cancer cells to carboplatin
}

\author{
WEN SHU \\ Department of Obstetrics and Gynecology, The Second Affiliated Hospital of Chongqing Medical University, \\ Chongqing 400010, P.R. China
}

Received July 18, 2016; Accepted December 19, 2017

DOI: $10.3892 / 01.2018 .9232$

\begin{abstract}
Ovarian cancer, one of the most common types of cancer, has the highest mortality among all gynecological malignancies. The development of acquired drug resistance is the leading cause of chemotherapy failure. To study the mechanism underlying drug resistance in ovarian cancer, a drug-resistant ovarian cancer SKOV3 cell line was developed using the chemotherapeutic agent carboplatin (SKOV3-Carb) in the present study. It has been reported that high-mobility group protein box-1 (HMGB1) is associated with the chemoresistance of tumor cells. Therefore, the probable involvement of HMGB1 in the development of carboplatin resistance in ovarian cancer SKOV3 cells was investigated. HMGB1 has been reported to be overexpressed in carboplatin-resistant SKOV3-Carb cells compared with control SKOV3 cells. Subsequently, the expression of HMGB1 was silenced by small interference RNA technology. Reverse transcription-quantitative polymerase chain reaction and western blot analysis indicated that mRNA and protein expression levels of HMGB1 were significantly inhibited in HMGB1-silenced cells. Cell proliferation and apoptosis analyses were performed to evaluate the effect of HMGB1 silencing on resistant ovarian cancer cells. An MTT assay revealed that the proliferation of HMGB1-silenced SKOV3 and SKOV3-Carb cells were decreased compared with the proliferation of non-silenced control cells. Additionally, HMGB1 protein expression levels in SKOV3 cells, but not in SKOV3-Carb cells, were decreased in response to carboplatin treatment. Annexin V-fluorescein isothiocyanate/propidium iodide staining demonstrated that HMGB1 silencing enhanced the effects of carboplatin in inducing the apoptosis of SKOV3-Carb cells relative to HMGB1 non-silenced control cells. The results of the present study suggested that HMGB1 may be involved in the development of carboplatin resistance
\end{abstract}

Correspondence to: Dr Wen Shu, Department of Obstetrics and Gynecology, The Second Affiliated Hospital of Chongqing Medical University, 74 Linjiang Road, Chongqing 400010, P.R. China E-mail: shwensw@163.com

Key words: high-mobility group protein box-1, drug resistant, ovarian cancer, carboplatin, proliferation, apoptosis in ovarian cancer SKOV3 cells and that HMGB1 silencing may induce the sensitization of carboplatin-resistant ovarian cancer cells to carboplatin. Therefore, HMGB1 may be considered as a potent therapeutic target for increasing the sensitivity of ovarian cancer cells to carboplatin in order to improve the treatment and prognosis of ovarian cancer.

\section{Introduction}

Ovarian cancer, one of the most common types of cancer observed in females, has the highest mortality rate among all gynecological malignancies and demonstrates rapid disease progression (1). Approximately $70 \%$ of patients with ovarian cancer are diagnosed in the advanced stages of the disease and tumors are often accompanied by metastasis (2). Cytoreductive surgery coupled with adjuvant chemotherapy is widely applied as the standard treatment for ovarian cancer $(3,4)$. Although the survival rate of patients with ovarian cancer has improved in recent decades, almost all patients eventually experience tumor recurrence due to resistance to chemotherapy agents, resulting in a poor prognosis and a high mortality rate (5). Carboplatin is a chemotherapy drug used in the treatment of a number of types of cancer, including ovarian, lung, breast, cervical and esophageal cancer, and central nervous system tumors, due to its easy administration, low toxicity and high patient tolerance $(6,7)$. Similarly to cisplatin, carboplatin belongs to the group of platinum-based antineoplastic agents, interacts with DNA in order to interfere with DNA repair, and inhibits reproduction and general cell function, but demonstrates fewer side effects compared with cisplatin (8). However, the development of resistance to carboplatin in tumor cells causes patient insensitivity to carboplatin chemotherapy and eventually reduces treatment outcome. Therefore, the resistance of carboplatin is yet to be resolved and the identification of suitable molecular targets responsible for chemosensitivity to carboplatin is required in order for the treatments and prognosis of ovarian cancer to be improved.

High mobility group protein box-1 (HMGB1) is a highly conserved non-histone nuclear protein that exhibits dual function (9). HMGB1 serves an important structural function in chromatin organization, regulating transcription by binding DNA and promoting protein assembly on specific DNA targets within the nucleus (10-12). HMGB1 was also reported to be a critical cytokine in the cytoplasm that is 
responsible for mediating a wide range of physiological and pathological responses, including inflammation, infection and injury response, and regulating cell differentiation and motility (13-15). HMGB1 was reported to serve a crucial role in numerous human diseases, including arthritis (16), sepsis (17), Alzheimer's disease (18), and cardiovascular disease (19). Additionally, HMGB1 was implicated in the progression and development of several types of cancer, including lymphoma (20), and breast (21), lung (22), liver (23), stomach (24), colon (25), prostate (26) and ovarian cancer (27). HMGB1 overexpression was revealed to be involved in the evasion of apoptosis, abnormal proliferation and metastasis of tumor cells (28). Higher HMGB1 expression levels were detected in ovarian cancer tissues compared with expression in normal ovarian tissues (29); and high HMGB1 expression was reported to be associated with poor prognosis (30), suggesting that HMGB1 may be a potential target for the diagnosis and treatment of ovarian cancer. Furthermore, it was demonstrated that high HMGB1 expression in cancer cells may be induced by several chemotherapeutic agents, which may lead to the poor prognosis (31), suggesting that HMGB1 may be associated with drug resistance. To the best of our knowledge, the association between HMGB1 and resistance of ovarian cancer to carboplatin has not previously been investigated. In the present study, carboplatin-resistant ovarian cancer cells were developed and the effects of HMGB1 on the sensitivity of the resistant ovarian cancer cells to carboplatin were investigated.

\section{Materials and methods}

Cell culture. The human ovarian cancer SKOV3 cell line was purchased from the Cell Resource Center, Institute of Basic Medical Sciences, Chinese Academy of Medical Sciences (Beijing, China). SKOV3 cells were cultured in Dulbecco's modified Eagle's medium (DMEM; Gibco; Thermo Fisher Scientific, Inc., Waltham, MA, USA), supplemented with $10 \%$ fetal bovine serum (FBS; Gibco; Thermo Fisher Scientific, Inc.), $100 \mu \mathrm{g} / \mathrm{ml}$ streptomycin and $100 \mathrm{U} / \mathrm{ml}$ penicillin (Invitrogen; Thermo Fisher Scientific, Inc.) in a $37^{\circ} \mathrm{C}$ incubator with humidified atmosphere containing $5 \% \mathrm{CO}_{2}$.

Development of carboplatin-resistant cells. To develop drug resistant cells, SKOV3 cells were exposed to increasing concentrations of carboplatin ranging between 10 and $100 \mu \mathrm{g} / \mathrm{ml}$ in DMEM medium. To begin with, cells were cultured on $60-\mathrm{mm}$ culture plates for $24 \mathrm{~h}$ at $37^{\circ} \mathrm{C}$. Carboplatin $(10 \mu \mathrm{g} / \mathrm{ml})$ was then added for a further $48 \mathrm{~h}$. Subsequently, the medium was replaced with fresh drug-free DMEM medium. When cells reached $80 \%$ confluency, cells were trypsinized, re-plated and re-treated with $20 \mu \mathrm{g} / \mathrm{ml}$ carboplatin. This process was repeated until clones demonstrated resistance to $100 \mu \mathrm{g} / \mathrm{ml}$ carboplatin. Following prolonged treatment ( 2 months) with increasing doses of carboplatin, living clones were collected and named as carboplatin-resistant SKOV3 cells (SKOV3-Carb), and were prepared for follow-up experiments.

RNA interference of HMGB1. Small interfering (si)RNAs against HMGB1 (siHMGB1; Sense: 5'-GGAAGUUUCUAC UGUAUAGTT-3'; Antisense: 5'-CUAUACAGUAGAAAC UUCCTT-3') and the negative control (siCtrl; Sense: 5'-UUC
UCCGAACGUGUCACGUTT-3'; Antisense: 5'-ACGUGA CACGUUCGGAGAATT-3') were designed and chemically synthesized by Shanghai GenePharma Co., Ltd., (Shanghai, China). A total of 75 pM siRNAs were transfected into SKOV3 and SKOV3-Carb cells $\sim 50-70 \%$ confluence in a six-well plate using Lipofectamine ${ }^{\circledR} 2000$ (Invitrogen; Thermo Fisher Scientific, Inc.), according to the manufacturer's protocol. Cells were lysed $24 \mathrm{~h}$ after transfection, and the mRNA and protein expression levels of HMGB1 were then analyzed by reverse transcription-quantitative polymerase chain reaction (RT-qPCR) and western blot analysis, respectively.

Western blot analysis. Total protein was extracted from the SKOV3 cells and SKOV3-Carb cells using a Total Protein Extraction kit (Nanjing KeyGen Biotech Co., Ltd., Nanjing, China), according to the manufacturer's protocol. Following centrifugation at $12,000 \mathrm{xg}$ for $10 \mathrm{~min}$ at $4^{\circ} \mathrm{C}$, the supernatant was collected and quantified using a bicinchoninic acid quantification kit (Beyotime Institute of Biotechnology, Haimen, China). The proteins $(50 \mu \mathrm{g})$ were separated by $12 \%$ SDS-PAGE and were transferred onto polyvinylidene fluoride membranes (EMD Millipore, Billerica, MA, USA). The membranes were blocked with 5\% skimmed dried milk in Tris-buffered saline with Tween-20 for $1 \mathrm{~h}$ at room temperature, and were incubated with mouse monoclonal HMGB1 (1:2,000; cat. no. ab77302; Abcam, Cambridge, UK) and mouse monoclonal GAPDH (1:5,000; cat. no. sc365062; Santa Cruz Biotechnology, Inc., Dallas, TX, USA) primary antibodies overnight at $4^{\circ} \mathrm{C}$. Membranes were subsequently incubated with a goat anti-mouse horseradish peroxidase-conjugated immunoglobulin G secondary antibody (1:2,000; cat. no. sc-2005; Santa Cruz Biotechnology, Inc.) for $2 \mathrm{~h}$ at room temperature. Visualization was performed using ECL-detecting reagent (GE Healthcare, Chicago, IL, USA). The protein blots were quantified by densitometry using Image J version 1.47 software (National Institutes of Health, Bethesda, MD, USA), and the expression was normalized to the internal reference GAPDH.

$R T-q P C R$. Total RNA was extracted from SKOV3 and SKOV3-Carb cells using a Total RNA Mini Plus kit (A\&A Biotechnology, Gdynia, Poland), according to the manufacturer's protocol. cDNA was obtained by RT-qPCR using a RevertAid $^{\mathrm{TM}}$ First Strand cDNA Synthesis kit (Fermentas; Thermo Fisher Scientific, Inc., Pittsburgh, PA, USA) in $50 \mu 1$ reactions with an initial denaturation at $94^{\circ} \mathrm{C}$ for $3 \mathrm{~min}$, followed by 35 cycles of $94^{\circ} \mathrm{C}$ for $30 \mathrm{sec}, 60^{\circ} \mathrm{C}$ for $30 \mathrm{sec}$, and $72^{\circ} \mathrm{C}$ for $30 \mathrm{sec}$ and a final elongation step of $72^{\circ} \mathrm{C}$ for $5 \mathrm{~min}$, and then was amplified using a TaqMan ${ }^{\circledR}$ Gene Expression assay (Applied Biosystems; Thermo Fisher Scientific, Inc.) with fluorogenic fluorescein amidite-labeled probes using specific primers for target proteins. PCR involved 40 amplification cycles of $94^{\circ} \mathrm{C}$ for $10 \mathrm{sec}, 53^{\circ} \mathrm{C}$ for $30 \mathrm{sec}$, and $72^{\circ} \mathrm{C}$ for $40 \mathrm{sec}$, followed by final extension at $72^{\circ} \mathrm{C}$ for $10 \mathrm{~min}$. The primers were as follows: HMGB1 F, 5'-TACCGCCCC AAAATCAAAGG-3' and R, 5'-TCTCATAGGGCTGCTTGT CA-3'; GAPDH F, 5'-CATGGCCTTCCGTGTTCCTA-3' and R, 5'-CCTGCTTCACCACCTTCTTGAT-3'. The real-time fluorescence detection was performed using the ABI PRISM 7700 Sequence Detector (Perkin-Elmer Applied Biosystems; Thermo Fisher Scientific, Inc.). HMGB1 mRNA expression 

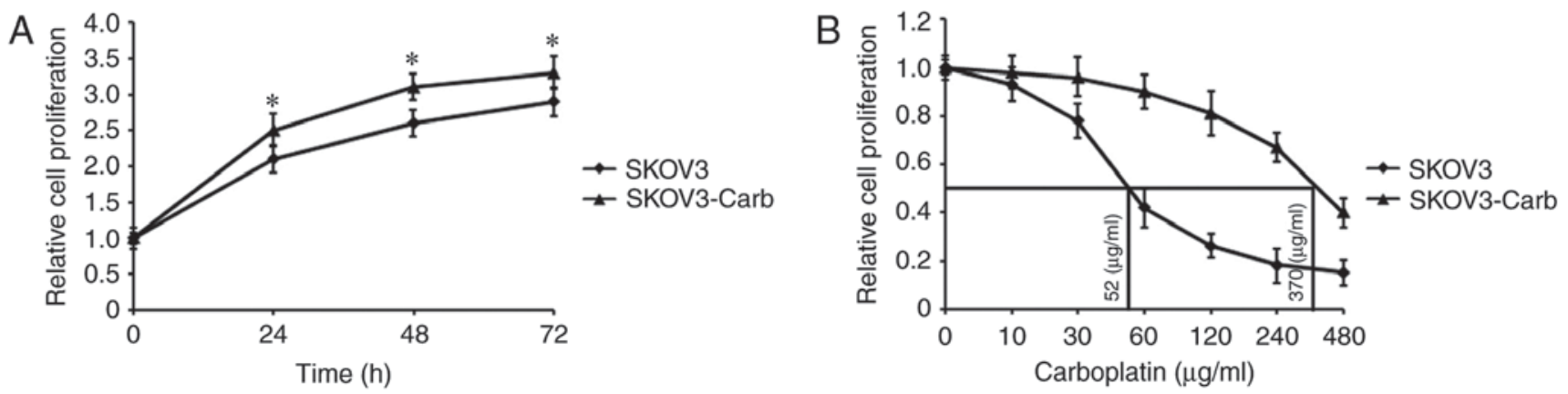

Figure 1. Characterization of SKOV3-Carb and SKOV3 cells. (A) Ovarian cancer SKOV3-Carb and SKOV3 cells were maintained in 96-well plates and cell proliferation at 24, 48 and $72 \mathrm{~h}$ was assessed using an MTT assay. Proliferation curves of the two cells are presented. (B) Cells were incubated in $100 \mu 1$ medium for $24 \mathrm{~h}$, prior to being treated with $0,10,30,60,120,240$ and $480 \mu \mathrm{g} / \mathrm{ml}$ carboplatin for $72 \mathrm{~h}$. Cell proliferation was evaluated using an MTT assay and half-maximal inhibitory concentration values of the two cells were calculated. SKOV3-carb, carboplatin-resistant SKOV3 cells. "P<0.05 vs. SKOV3 cells

was calculated using the formula $2^{-\Delta \Delta C q}(32)$ and was normalized to the level of GAPDH. The relative levels of HMGB1 mRNA are presented as a percentage of the control.

Proliferation assay. Cell proliferation was evaluated using an MTT assay (Sigma Aldrich; Merck KGaA, Darmstadt, Germany). A total of 2,000 untransfected SKOV3 and SKOV3-Carb cells were seeded onto each well of a 96-well plate in $100 \mu \mathrm{l}$ DMEM and were incubated with or without $10,30,60,120,240,480 \mu \mathrm{g} / \mathrm{ml}$ carboplatin for 24,48 and $72 \mathrm{~h}$ at $37^{\circ} \mathrm{C}$ in a $5 \% \mathrm{CO}_{2}$ incubator. Subsequently, cells were incubated with $20 \mu \mathrm{l}$ of $5 \mathrm{mg} / \mathrm{ml}$ MTT (Sigma-Aldrich; Merck $\mathrm{KGaA}$ ) for $4 \mathrm{~h}$ at $37^{\circ} \mathrm{C}$ incubator, prior to being lysed for $10 \mathrm{~min}$ by addition of $200 \mu \mathrm{l}$ dimethyl sulfoxide (OriGene Technologies, Inc., Rockville, MD, USA) used to dissolve the purple formazan. Absorbance was measured at $490 \mathrm{~nm}$ using a Rainbow microplate reader (Tecan Group Ltd., Grödig, Austria). Cell proliferation was expressed as a percentage of the untreated control.

Apoptosis assay. Cells were cultured to $80 \%$ confluence and were treated with $50 \mu \mathrm{g} / \mathrm{ml}$ carboplatin for $48 \mathrm{~h}$ at $37^{\circ} \mathrm{C}$. Apoptosis was analyzed using an Annexin V-fluorescein isothiocyanate (FITC)/propidium iodide (PI) assay, according to the manufacturer's protocol. The amount of phosphatidylserine on the outer surface of the plasma membrane (a biochemical alteration unique to the membranes of apoptotic cells) and the amount of PI, a dye that easily enters dead cells or cells in the late stages of apoptosis and binds DNA but not the plasma membrane of viable cells, were detected. Fluorescence was detected using a FACSCalibur flow cytometer by fluorescence activated cell sorter analysis, and data were analyzed using CellQuestPro version 5.2 software (BD Biosciences, San Jose, CA, USA). Cells with phosphatidylserine on their surface were considered to be apoptotic.

Statistical analysis. Data were obtained from at least three experiments. Statistical analysis was performed using SPSS 13.0 (SPSS, Inc., Chicago, IL, USA) for Microsoft ${ }^{\mathrm{TM}}$ Windows (Microsoft Corporation, Redmond, WA, USA). Data are presented as the mean \pm standard error of the mean. One-way analysis of variance was used to assess differences between groups. The Duncan method was employed for pairwise comparison, followed by Bonferroni's correction. $\mathrm{P}<0.05$ was considered to indicate a statistically significant difference.

\section{Results}

Development of carboplatin-resistant ovarian cancer SKOV3 cells. To examine the mechanism underlying carboplatin resistance in ovarian cancer, a carboplatin-resistant ovarian cancer SKOV3 cell model (SKOV3-Carb) was generated. Cell proliferation was assessed using an MTT assay, and the proliferation of SKOV3-Carb and SKOV3 cells are presented in Fig. 1. The data demonstrated that SKOV3-Carb cells significantly proliferated more rapidly than SKOV3 cells at 24,48 and $72 \mathrm{~h}(\mathrm{P}=0.037, \mathrm{P}=0.018$ and $\mathrm{P}=0.041$, respectively; Fig. 1A). Additionally, the half-maximal inhibitory concentration $\left(\mathrm{IC}_{50}\right)$ of carboplatin was determined by exposing SKOV3-Carb and SKOV3 cells to various concentrations of carboplatin for $72 \mathrm{~h}$; the $\mathrm{IC}_{50}$ values of the two types of cell were calculated to be 370 and $52 \mu \mathrm{g} / \mathrm{m}$, respectively (Fig. 1B).

Expression of HMGB1 in SKOV3-Carb and SKOV3 cells. To determine whether HMGB1 is associated with the development of carboplatin resistance in SKOV3-Carb cells, HMGB1 expression was analyzed. RT-qPCR and western blot analysis demonstrated that both mRNA and protein expression levels of HMGB1 in SKOV3-Carb cells were significantly higher compared with that in SKOV3 cells $(\mathrm{P}=0.008$ and $\mathrm{P}=0.035$, respectively; Fig. 2A and B). The results of the present study suggested that HMGB1 may be associated with the resistance development of ovarian cancer SKOV3 cells to carboplatin.

HMGB1 silencing re-sensitizes resistant cells to carboplatin. To investigate the effect of HMGB1 on the development of carboplatin resistance in ovarian cancer SKOV3 cells, the corresponding siRNA of HMGB1 was used to decrease the expression of HMGB1. RT-qPCR and western blot analysis indicated that HMGB1 mRNA and protein expression in HMGB1-silenced cells was significantly reduced by 80 and $71 \%$ for SKOV3 cells, 73 and $78 \%$ for SKOV3-Carb cells, respectively, compared with expression in non-silenced control cells $(\mathrm{P}=0.006$ for SKOV3 and $\mathrm{P}=0.007$ for SKOV3-Carb, Fig. 3A; $\mathrm{P}=0.043$ for 


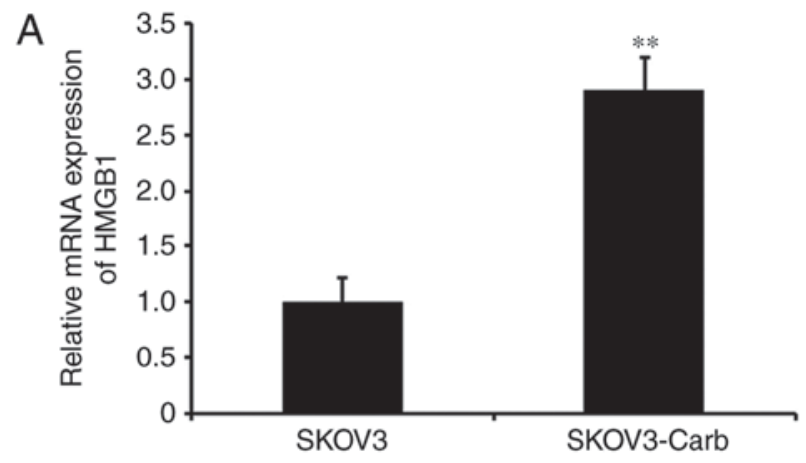

B
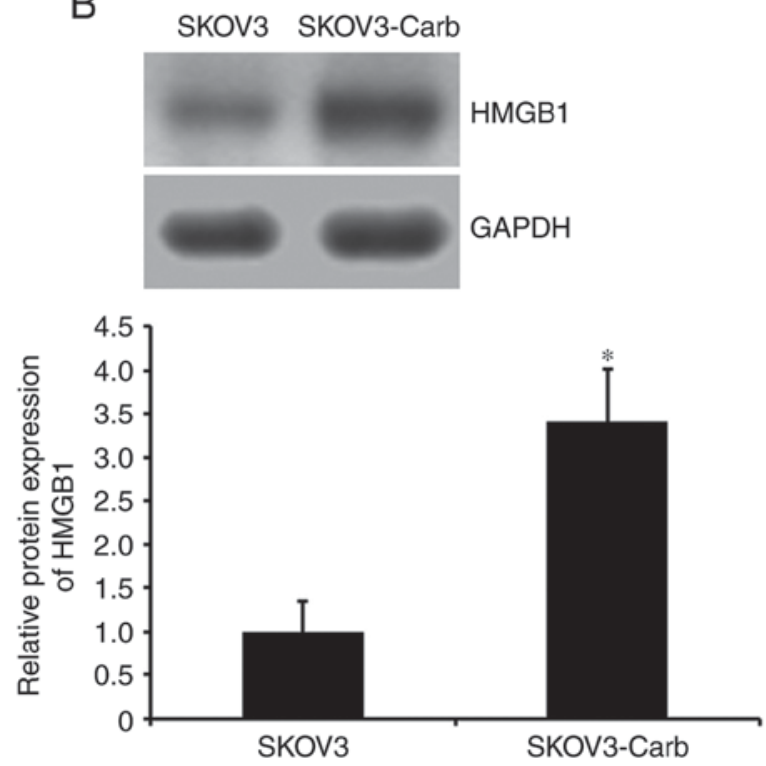

Figure 2. Expression of HMGB1 in SKOV3-Carb and SKOV3 cells. (A) Cells were cultured to $80 \%$ confluence, prior to being collected. Total RNA was extracted from cells to evaluate mRNA expression of HMGB1 in SKOV3-Carb cells by reverse-transcription-quantitative polymerase chain reaction. ${ }^{* *} \mathrm{P}<0.01$ vs. SKOV3 cells. (B) Cells were lysed and collected, and then total protein was extracted from cells; HMGB1 protein expression levels were examined by western blot analysis using an anti-HMGB1 antibody. GAPDH was used as an internal reference gene. The protein blots were quantified by densitometry. Data are presented as the mean \pm standard error of the mean of three independent experiments. " $\mathrm{P}<0.05$ vs. SKOV 3 cells. HMGB1, high mobility group protein box-1; SKOV3-carb, carboplatin-resistant SKOV3 cells.

SKOV3 and P=0.031 for SKOV3-Carb, Fig. 3B). SKOV3-Carb and SKOV3 cells were transiently transfected with control and HMGB1 siRNA, and were cultured in the presence or absence of $50 \mu \mathrm{g} / \mathrm{ml}$ carboplatin for $72 \mathrm{~h}$. Cell proliferation was analyzed using an MTT assay. The results demonstrated that the proliferative ability of HMGB1-silenced SKOV3-Carb cells was significantly suppressed in response to carboplatin treatment in comparison with carboplatin-treated SKOV3-Carb cells transfected with the control siRNA. Additionally, the proliferative ability of the SKOV3-Carb cells transfected with siCtrl was not markedly affected by carboplatin treatment and revealed slightly increased survival cells compared with the SKOV 3 cells $(\mathrm{P}=0.038$ and $\mathrm{P}=0.046$, respectively; Fig. $3 \mathrm{C})$. However, under identical experimental conditions no significant difference was observed in the proliferation between HMGB1-silenced and non-silenced SKOV3 cells.
HMGB1 silencing promotes the SKOV3-Carb cell apoptosis induced by carboplatin treatment. In order to elucidate the mechanism underlying HMGB1 silencing-induced sensitization of SKOV3-Carb cells to carboplatin, apoptosis was evaluated using an Annexin V-FITC/PI assay. SKOV3-Carb and SKOV3 cells were treated with control and HMGB1 siRNA, and were exposed to $50 \mu \mathrm{g} / \mathrm{ml}$ carboplatin for $48 \mathrm{~h}$. The data indicated that carboplatin treatment induced the apoptosis of both siHMGB1- and siCtrl-transfected SKOV3 cells compared with apoptosis in the corresponding untreated control cells ( $\mathrm{P}=0.036$ and $\mathrm{P}=0.029$, respectively; Fig. 4A). Notably, HMGB1 silencing significantly stimulated the apoptosis mediated by carboplatin in SKOV3-Carb cells relative to that of siCtrl-transfected SKOV3-Carb cells $(\mathrm{P}=0.012$; Fig. 4B). However, carboplatin treatment did not significantly induce apoptosis in siCtrl-transfected resistant SKOV3-Carb cells compared with the untreated siCtrl-transfected control cells. These results suggested that HMGB1 may be associated with the resistance of ovarian cancer SKOV3 cells to carboplatin and that HMGB1 silencing may increase the sensitivity of resistant cells to carboplatin by increasing the apoptosis induced by carboplatin treatment.

\section{Discussion}

Ovarian cancer is the fifth most common cause of cancerassociated mortality in women worldwide, and has the highest rates of mortality among all gynecological malignancies in 2014 (1). Non-metastatic ovarian cancer may be curable with surgery, while surgery is insufficient for cancer treatment in cases of invasion and metastasis (33). In these cases, chemotherapy is the alternative treatment strategy; however, the development of drug resistance during treatment widely limits chemotherapeutic effectiveness, leading to a poor prognosis (33). Tumor cells treated with drugs may not only obtain resistance to the agent originally used, but may also exhibit cross resistance to other agents, which may be mediated by numerous molecular mechanisms (34-36). Therefore, investigating the underlying mechanism of chemoresistance is important for improving cancer treatment.

In the present study, a drug-resistant ovarian cell model was constructed using various concentrations of carboplatin, which simulated the condition of drug resistance development in vivo. The growth of carboplatin-resistant ovarian cancer SKOV3 cells, SKOV3-Carb and SKOV3 cells were compared to observe the cellular resistance phenotype. It was demonstrated that the proliferation rate of SKOV3-Carb cells was faster and was decreased by carboplatin treatment to a lesser extent than that of SKOV3 cells. Additionally, it has been reported that elevated HMGB1 expression may be induced by numerous chemotherapeutic agents, including cisplatin, Adriamycin and methotrexate in lung cancer cells (31). Carboplatin, as well as cisplatin, belongs to the group of platinum-based antineoplastic agents. Therefore, it is possible that HMGB1 expression may also be increased by carboplatin treatment. HMGB1 is a cancer-promoting protein, closely associated with tumorigenesis and development, by promoting cell proliferation and motility. Increased HMGB1 expression has been detected in several types of human cancer (20-27). HMGB1 was reported to promote cell proliferation and 
A

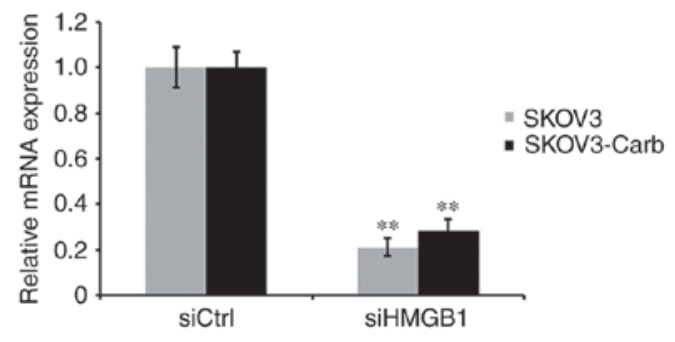

C

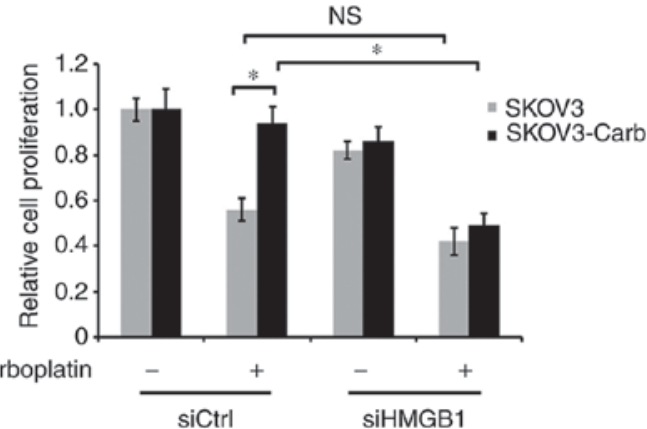

B
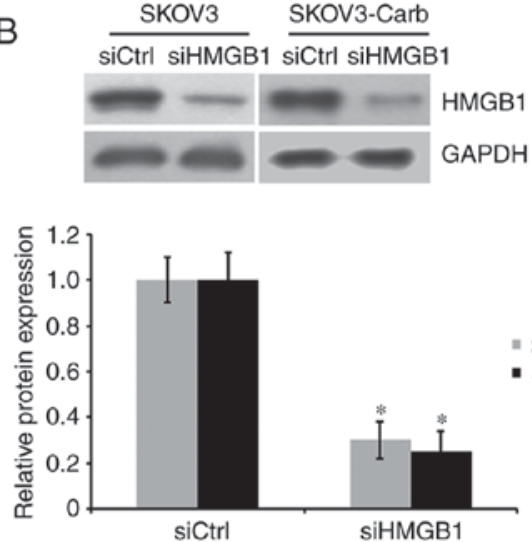

= SKOV3

- SKOV3-Carb

Figure 3. HMGB1 silencing sensitizes resistant SKOV3-Carb cells to carboplatin. Cells were transfected with siCtrl or siHMGB1 for $48 \mathrm{~h}$. (A) mRNA and (B) protein expression levels of HMGB1 in SKOV3-Carb and SKOV3 cells were analyzed by reverse-transcription-quantitative polymerase chain reaction and western blot analysis, respectively. ${ }^{* *} \mathrm{P}<0.01$ vs. control. (C) SKOV3-Carb and SKOV3 cells transfected with siCtrl or siHMGB1 for $24 \mathrm{~h}$ were incubated with fresh medium with or without $50 \mu \mathrm{g} / \mathrm{ml}$ carboplatin for an additional $72 \mathrm{~h}$. Cell proliferation was detected using an MTT assay. "P<0.05. NS, not significant; siCtrl, negative control small interfering RNA; siHMGB1, high mobility group protein box-1 small interfering RNA; SKOV3-carb, carboplatin-resistant SKOV3 cells.

A

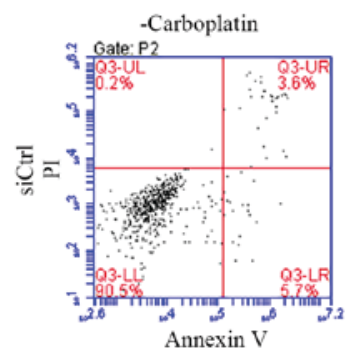

-Carboplatin

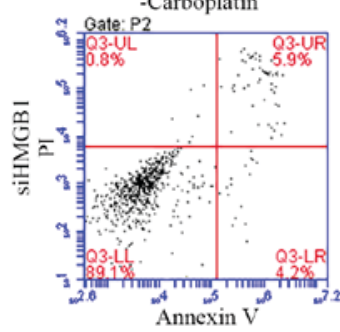

SKOV3
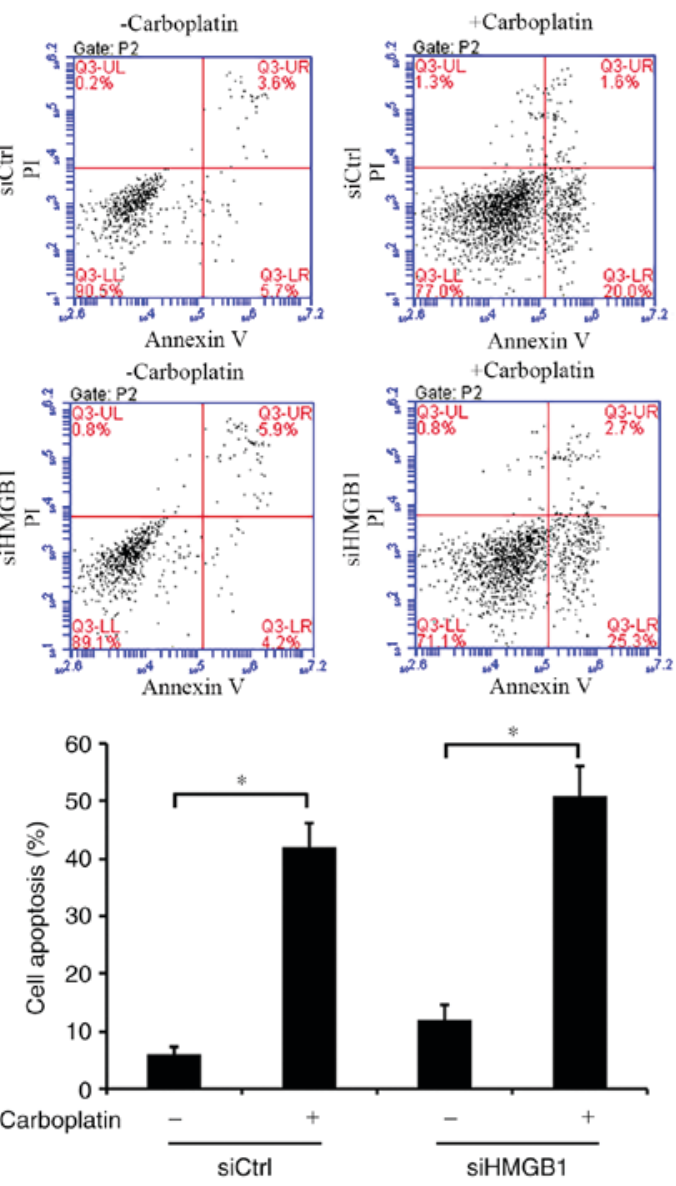

B

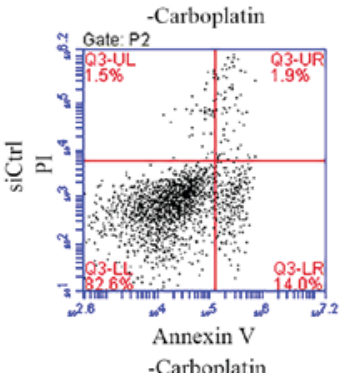

SKOV3-Carb
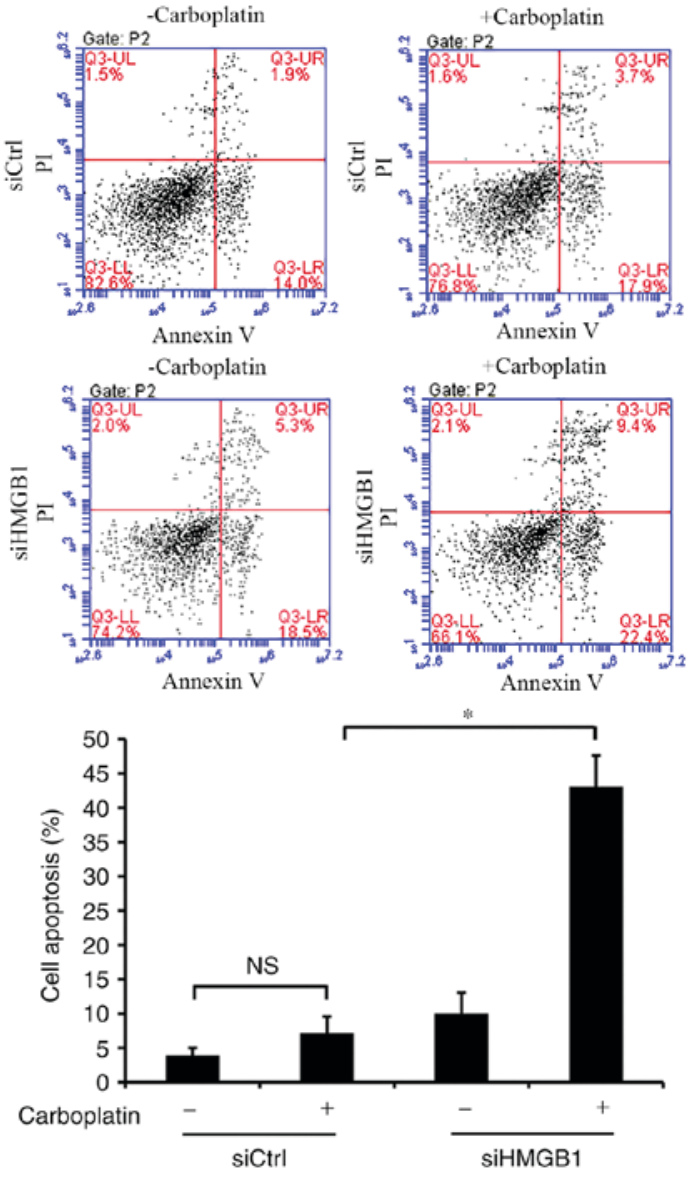

Figure 4. Effect of HMGB1 silencing on the apoptosis induced by carboplatin treatment in SKOV3-Carb cells. (A) SKOV3 and (B) SKOV3-Carb cells were transfected with siCtrl or siHMGB1 for $24 \mathrm{~h}$, prior to being exposed to $50 \mu \mathrm{g} / \mathrm{ml}$ carboplatin for $48 \mathrm{~h}$. Apoptosis of SKOV3 and SKOV3-Carb cells was evaluated using an Annexin V-fluorescein isothiocyanate/propidium iodide assay. ${ }^{*} \mathrm{P}<0.05$. NS, not significant; siCtrl, negative control small interfering RNA; siHMGB1, high mobility group protein box-1 small interfering RNA; SKOV3-carb, carboplatin-resistant SKOV3 cells. 
invasion, and to inhibit cell apoptosis in osteosarcoma MG-63 cells (28). Additionally, HMGB1 overexpression was reported to be associated with the proliferation and metastasis of lung adenocarcinoma cells (37). Furthermore, higher HMGB1 expression was observed in ovarian cancer compared with in normal ovarian tissues (29), and high HMGB1 expression was reported to be correlated with poor prognosis (30). The presented study demonstrated that HMGB1 expression levels were increased in resistant SKOV3-Carb cells compared with expression in SKOV3 cells, suggesting that HMGB1 may be associated with the development of resistance to carboplatin in ovarian cancer cells.

It was reported that interference with HMGB1 significantly accelerated apoptosis and suppressed cellular motility ability in breast cancer MCF-7 cells (38). Absence of HMGB1 inhibited the growth and invasion of colon cancer LoVo cells (39). In the present study, to verify the aforementioned hypothesis, the expression of HMGB1 was effectively inhibited by employing its corresponding siRNA. The results of the present study revealed that HMGB1 silencing enhanced the inhibitory effect on proliferation and promoted the apoptosis induced by carboplatin treatment in resistant SKOV3 cells and thus, restored the carboplatin sensitivity to the cells. This suggested that HMGB1 may serve an important role in the modulation of carboplatin resistance in ovarian cancer SKOV3 cells. Therefore, the results of the present study indicated that the chemotherapeutic agent, carboplatin, combined with the targeted therapy of resistance-associated genes, including HMGB1, may serve as a more effective therapy for ovarian cancer. However, whether cross resistance of SKOV3-Carb cells to other therapeutic drugs is generated or whether other factors are involved in the development of resistance is yet to be investigated, which may be important in the prognosis and treatment of cancer. The present study provided a promising clinical therapeutic strategy for ovarian cancer. To verify the universality of the therapeutic strategy in ovarian cancer, additional ovarian cancer cell lines are required to complete this study.

\section{Acknowledgements}

Not applicable.

\section{Funding}

No funding was received.

\section{Availability of data and materials}

The datasets used and/or analyzed during the current study are available from the corresponding author on reasonable request.

\section{Authors' contributions}

All the works about this manuscript were carried out by WS, including conception and design of the research and revision of the manuscript, acquisition of data, analysis and interpretation of data and statistical analysis and drafting the manuscript.

\section{Ethics approval and consent to participate}

Not applicable.

\section{Patient consent for publication}

Not applicable.

\section{Competing interests}

The authors declare that they have no competing interests.

\section{References}

1. Ferlay J, Shin HR, Bray F, Forman D, Mathers C and Parkin DM: GLOBOCAN 2008 v1.2. Cancer incidence, mortality and prevalence worldwide. IARC CancerBase No. 10 (Internet). IARC Press, Lyon, 2010.

2. Chen WQ, Zhang SW, Zou XN and Zhao P: Cancer incidence and mortality in China, 2006. Chin J Cancer Res 23: 3-9, 2011.

3. du Bois A, Quinn M, Thigpen T, Vermorken J, Avall-Lundqvist E, Bookman M, Bowtell D, Brady M, Casado A, Cervantes A, et al: 2004 consensus statements on the management of ovarian cancer: Final document of the 3rd international gynecologic cancer intergroup ovarian cancer consensus conference (GCIG OCCC 2004). Ann Oncol 16: viii7-viii12, 2005.

4. Li R and Linghu H: Treatment progress in epithelial ovarian cancer. J Int Obstet Gynecol 37: 277-280, 2010 (In Chinese).

5. Brouwer-Visser J, Lee J, McCullagh K, Cossio MJ, Wang Y and Huang GS: Insulinlike growth factor 2 silencing restores taxol sensitivity in drug resistant ovarian cancer. PLoS One 9: e100165, 2014.

6. Wheate NJ, Walker S, Craig GE and Oun R: The status of platinum anticancer drugs in the clinic and in clinical trials. Dalton Trans 39: 8113-8127, 2010.

7. Apps MG, Choi EH and Wheate NJ: The state-of-play and future of platinum drugs. Endocr Relat Cancer 22: R219-R233, 2015.

8. Wikipedia, the free encyclopedia: Carboplatin. https:// en.wikipedia.org/wiki/Carboplatin. Accessed June 2, 2016.

9. Taniguchi N, Yoshida K, Ito T, Tsuda M, Mishima Y, Furumatsu T, Ronfani L, Abeyama K, Kawahara K, Komiya S, et al: Stagespecific secretion of HMGB1 in cartilage regulates endochondral ossification. Mol Cell Biol 27: 5650-5663, 2007.

10. Lotze MT and Tracey KJ: High-mobility group box 1 protein (HMGB1): Nuclear weapon in the immune arsenal. Nat Rev Immunol 5: 331-342, 2005.

11. Muller S, Scaffidi P, Degryse B, Bonaldi T, Ronfani L, Agresti A, Beltrame $M$ and Bianchi ME: New EMBO members' review: The double life of HMGB1 chromatin protein: architectural factor and extracellular signal. EMBO J 20: 4337-4340, 2001.

12. Tang D, Kang R, Zeh HJ III and Lotze MT: High-mobility group box 1 and cancer. Biochim Biophys Acta 1799: 131-140, 2010.

13. Bell CW, Jiang W, Reich CF and Pisetsky DS: The extracellular release of HMGB1 during apoptotic cell death. Am J Physiol Cell Physiol 291: C1318-C1325, 2006.

14. LeBlanc PM, Doggett TA, Choi J, Hancock MA, Durocher Y, Frank F, Nagar B, Ferguson TA and Saleh M: An immunogenic peptide in the a-box of HMGB1 protein reverses apoptosis-induced tolerance through RAGE receptor. J Biol Chem 289: 7777-7786, 2014.

15. Lotze MT and DeMarco RA: Dealing with death: HMGB1 as a novel target for cancer therapy. Curr Opin Investig Drugs 4: 1405-1409, 2003.

16. Park SY, Lee SW, Kim HY, Lee WS, Hong KW and Kim CD: HMGB1 induces angiogenesis in rheumatoid arthritis via HIF-1 $\alpha$ activation. Eur J Immunol 45: 1216-1227, 2015.

17. Singh A, Feng Y, Mahato N, Li J, Wu C and Gong J: Role of high-mobility group box 1 in patients with acute obstructive suppurative cholangitis-induced sepsis. J Inflamm Res 8: 71-77, 2015.

18. Jang A, Liew H, Kim YM, Choi H, Kim S, Lee SH, Ohshima T, Mikoshiba K and Suh YH: p35 deficiency accelerates HMGB-1-mediated neuronal death in the early stages of an Alzheimer's disease mouse model. Curr Alzheimer Res 10: 829-843, 2013 
19. Park S, Yoon SJ, Tae HJ and Shim CY: RAGE and cardiovascular disease. Front Biosci (Landmark Ed) 16: 486-497, 2011.

20. Meyer A, Staratschek-Jox A, Springwald A, Wenk H, Wolf J, Wickenhauser C and Bullerdiek J: Non-Hodgkin lymphoma expressing high levels of the danger-signalling protein HMGB1. Leuk Lymphoma 49: 1184-1189, 2008.

21. Brezniceanu ML, Volp K, Bosser S, Solbach C, Lichter P, Joos S and Zornig M: HMGB1 inhibits cell death in yeast and mammalian cells and is abundantly expressed in human breast carcinoma. FASEB J 17: 1295-1297, 2003.

22. Feng A, Tu Z and Yin B: The effect of HMGB1 on the clinicopathological and prognostic features of non-small cell lung cancer. Oncotarget 7: 20507-20519, 2016.

23. Cheng P, Dai W, Wang F, Lu J, Shen M, Chen K, Li J, Zhang Y, Wang C, Yang J, et al: Ethyl pyruvate inhibits proliferation and induces apoptosis of hepatocellular carcinoma via regulation of the HMGB1-RAGE, and AKT pathways. Biochem Biophys Res Commun 443: 1162-1168, 2014.

24. Akaike H, Kono K, Sugai H, Takahashi A, Mimura K, Kawaguchi Y and Fujii $\mathrm{H}$ : Expression of high mobility group box chromosomal protein-1 (HMGB-1) in gastric cancer. Anticancer Res 27: 449-457, 2007.

25. Kang HJ, Lee H, Choi HJ, Youn JH, Shin JS, Ahn YH, Yoo JS, Paik YK and Kim H: Non-histone nuclear factor HMGB1 is phosphorylated and secreted in colon cancers. Lab Invest 89: 948-959, 2009.

26. Gnanasekar M, Kalyanasundaram R, Zheng G, Chen A, Bosland MC and Kajdacsy-Balla A: HMGB1: A promising therapeutic target for prostate cancer. Prostate Cancer 2013: 157103,2013

27. Chen J, Liu X, Zhang J and Zhao Y: Targeting HMGB1 inhibits ovarian cancer growth and metastasis by lentivirus-mediated RNA interference. J Cell Physiol 227: 3629-3638, 2012.

28. Guo ZS, Liu Z, Bartlett DL, Tang D and Lotze MT: Life after death: targeting high mobility group box 1 in emergent cancer therapies. Am J Cancer Res 3: 1-20, 2013.

29. Machado L, Moseley P, Moss R, Nolan C, Rampage J, Chan S and Durrant LG: High-mobility group protein 1 (HMGB1) is an independent predictor of poor survival in ovarian cancer. In: Proceedings of the National Cancer Research Institute (NCRI) Cancer Conference, Liverpool, UK, 2014.
30. Zhi H, Ma HY and Chen XL: The changes and clinical significance of serum levels of HMGB1, VEGF before and after operation in patients with ovarian carcinoma. Hebei Med J 36: 1297-1299, 2014 (In Chinese).

31. Zhang R, Li Y, Wang Z, Chen L, Dong X and Nie X: Interference with HMGB1 increases the sensitivity to chemotherapy drugs by inhibiting HMGB1-mediated cell autophagy and inducing cell apoptosis. Tumour Biol 36: 8585-8592, 2015

32. Slack JL, Bi W, Livak KJ, Beaubier N, Yu M, Clark M, Kim SH, Gallagher RE and Willman CL: Pre-clinical validation of a novel, highly sensitive assay to detect PML-RARalpha mRNA using real-time reverse-transcription polymerase chain reaction. J Mol Diagn 3: 141-149, 2001.

33. Harding M: Ovarian cancer. https://patient.info/doctor/ovarian-cancer-pro. Accessed December 2, 2016.

34. Szakacs G, Paterson JK, Ludwig JA, Booth-Genthe C and Gottesman MM: Targeting multidrug resistance in cancer. Nat Rev Drug Discov 5: 219-234, 2006.

35. Germann UA and Chambers TC: Molecular analysis of the multidrug transporter, P-glycoprotein. Cytotechnology 27: 31-60, 1998.

36. Xu Y, Zhi F, Xu G, Tang X, Lu S, Wu J and Hu Y: Overcoming multidrug resistance in vitro and in vivo by a novel $\mathrm{P}$-glycoprotein inhibitor 1416. Biosci Rep 32: 559-566, 2012.

37. Sun KK, Ji C, Li X, Zhang L, Deng J, Zhong N and Wu XY: Overexpression of high mobility group protein $\mathrm{B} 1$ correlates with the proliferation and metastasis of lung adenocarcinoma cells. Mol Med Rep 7: 1678-1782, 2013.

38. Ni P, Zhang Y, Liu Y, Lin X, Su X, Lu H, Shen H, Xu W, Xu H and Su Z: HMGB1 silence could promote MCF-7 cell apoptosis and inhibit invasion and metastasis. Int J Clin Exp Pathol 8: 15940-15946, 2015.

39. Li Z, Wang H, Song B, Sun Y, Xu Z and Han J: Silencing HMGB1 expression by lentivirus-mediated small interfering RNA (siRNA) inhibits the proliferation and invasion of colorectal cancer LoVo cells in vitro and in vivo. Zhonghua Zhong Liu Za Zhi 37: 664-670, 2015 (In Chinese). 